\title{
Migrantes y refugiados: apuntes clave para un nuevo relato
}

\author{
María-José Aguilar-Idáñez \& Daniel Buraschi
}

\begin{abstract}
Resumen
Partiendo del significado delos datosmás recientes sobre desplazamientos forzosos, presentamos algunas herramientas conceptuales para interpretar la paradoja moral de la falta de reconocimiento de los derechos de las personas en busca de refugio. Nuestra propuesta de análisis se basa en la idea que la indiferencia y la justificación de la violencia hacia las personas desplazadas que piden socorro son el reflejo de la existencia de fronteras morales que les excluyen de nuestro espacio moral. Las fronteras morales, es decir el conjunto de imágenes, acciones, formas discursivas, esquemas mentales, emociones, sentimientos y símbolos que constituyen representaciones sociales compartidas, se construyen a través de la interacción, en la mediapolis, de un círculo vicioso racista entre medios de comunicación, discurso de las élites y discurso social, a través de un triple proceso de negación, diferenciación y construcción de la imagen de los refugiados y migrantes como amenaza. Finalmente apuntamos algunas estrategias de resistencia y un decálogo urgente para generar un nuevo relato que reencuadre la situación y permita construir una acogida comunitaria inclusiva.
\end{abstract}

Palabras clave:

migraciones forzosas; indiferencia; fronteras morales; mediapolis; comunicación participativa antirracista. 


\section{Migrants and refugees: key notes for new narratives}

Abstract: Based on the meaning of the most recent data on forced displacements, we present some conceptual tools in order to interpret the moral paradox of the lack of recognition of the rights of people seeking refuge. Our proposal for this analysis is based on the idea that both violence indifference and justification towards displaced people asking for aid are a reflection of the existence of moral boundaries which exclude them from our moral space. Moral boundaries, meaning the set of images, actions, discursive forms, mental schemes, emotions, feelings and symbols that constitute shared social representations, are constructed through the interaction of media, elite's speech and social speech, in a vicious cycle of racism. A triple process takes place: denial, differentiation and construction of the image of refugees and migrants as a threat. Finally we point out some strategies of resistance and an urgent decalogue of actions with the aim of generating a new narrative able to re-frame the situation and allowing to build an inclusive community hosting.

Key words: forced migrations; nonchalance; moral borders; mediapolis; participative antiracist communication.

\section{Migrantes e refugiados: apontes para um relato novo}

Resumo: Apresentamos neste artigo algumas ferramentas conceptuais para interpretar o paradoxo moral da falta de reconhecimento dos direitos das pessoas que buscam refúgio, considerando os recentes dados relacionados com as migrações forçadas. A nossa proposta de análise baseia-se na ideia que a indiferença e a justificação da violência contra as pessoas que tiveram que se deslocar procurando ajuda, refletem a existência de fronteiras morais que os excluem do nosso espaço moral. As fronteiras morais são o conjunto de imagens, ações, formas discursivas, esboços mentais, sentimentos e símbolos que constituem representações sociais compartilhadas, e são construídas pela interação, no mediapolis, de um círculo vicioso racista entre os media, o discurso das elites e o discurso social; por um triplo processo de negação, diferenciação e construção da imagem dos refugiados e migrantes como ameaça. Finalmente mostramos algumas estratégias de resistência e um decálogo urgente para gerar um relato novo que reenquadre a situação e permita construir um acolhimento inclusivo na comunidade.

Palavras-chave: migrações forçadas; indiferença; fronteiras morais; mediapolis; comunicaçao participativa antiracista.

\section{Migrants et réfugiés: les éléments clé pour un nouveau récit}

Résumé: Vis-à-vis les données les plus récentes sur les déplacements forcés, nous présentons quelques outils conceptuels afin d'interpréter le paradoxe moral sur le manque de reconnaissance des droits des personnes que demandent du refuge. Notre proposition d'analyse est basée sur l'idée que l'indifférence et la justification de la violence envers les personnes déplacées qui demandent de l'aide, sont le reflet d'une existence de frontières morales qui les excluent de notre espace moral. Ces frontières morales, c'est-à-dire, l'ensemble d'images, d'actions, de discours, de schémas mentaux, d'émotions, de sentiments et de symboles qui constituent les représentations sociales partagées, sont construites par le biais de l'interaction entre les médias, le discours d'élites et le discours social, dans un cercle vicieux raciste. II s'agit d'un triple procès: négation, différentiation et construction de l'image des réfugiés et migrants comme une menace. Finalement, nous formulons quelques stratégies de résistance et un décalogue urgent pour la création d'un nouveau récit qui permette de recadrer la situation, favorisant ainsi la construction d'un accueil communautaire inclusif.

Mots clé: migrations forcées; indifférence; frontières morales; mediapolis; communication participative antiraciste. 


\section{Algunos datos y su significado}

En 2016, por primera vez en la historia, se ha superado la cifra de 60 millones de personas refugiadas en el mundo. Según el ACNUR, 65,3 millones de personas se han visto obligadas a huir de sus hogares por la guerra o la persecución política, sexual, étnica, religiosa, etc. Todas estas personas, representadas en masa, sin nombre y aparentemente sin historia, son cifras que, si formaran un país, sería el vigésimo primero más poblado del mundo. Las personas forzadas a desplazarse se ubican en países del Sur-Global, es decir, son los países pobres los que acogen al 86 por ciento de los/ as refugiados/as del mundo. Los países ricos del Norte-Global acogen solamente a un 14 por ciento. Un millón de personas refugiadas Ilegaron a Europa durante 2015, casi 15.000 de ellas solicitaron asilo en España (apenas un 1 por ciento de la UE). En lo que va de año, la media de personas que entran en el espacio de la Unión Europea para pedir protección internacional es de unas 2.200 personas diarias. Pero mientras que la UE resolvió la mitad de esas solicitudes, España sólo resolvió el 31 por ciento. Es decir, nuestro país sólo ofreció protección a 1.020 personas y reubicó a 18 personas refugiadas de las 16.000 comprometidas. Considerando la totalidad de personas llegadas a Europa (soliciten o no refugio), sólo el 0,4 por ciento se producen a través de las costas españolas, a pesar del falso rumor de que "nos invaden".

La Europa que regatea las cuotas de acogida y retrasa ya casi dos años las medidas que se comprometió a adoptar a mediados de 2015, es paradójicamente rápida a la hora de reforzar el blindaje de las fronteras, levantar o reforzar vallas: aproximadamente, 260 kilómetros de cemento, concertinas y alambradas se han puesto en pie en los últimos años, sirviendo, sobre todo, para representar la insolidaridad institucional y la crisis de valores a la que se enfrenta. Este blindaje europeo provoca que miles de personas se vean obligadas a optar por rutas cada vez más inseguras. La lógica de invertir en más vallas y controles para intentar evitar la llegada de personas no tiene sentido. Así, solo aumenta el peligro y el sufrimiento humano de quienes huyen del terror ya que, ante la falta de vías legales para obtener protección (posibilidad de solicitar asilo en consulados de terceros países y embajadas, visados humanitarios, etc.) las personas refugiadas deben emprender peligrosas rutas para llegar a un país europeo. Muchas de ellas pierden su vida en el Mediterráneo, que se ha convertido en la ruta más peligrosa del mundo y la fosa común más grande del planeta, con más de 25.000 muertes en los últimos 15 años, más de 3.700 sólo en 2015 y en otoño de 2016 esa cifra ya superaba las 4.700 (aunque en realidad son muchas más, ya que en esa cifra no se contabilizan los barcos que se hunden sin que se tenga noticia de ellos o sin que haya sobrevivientes).

Son los Estados miembros de la Unión Europea los que deben dar una respuesta acorde con los derechos humanos y basada en la propia legislación internacional y 
europea en materia de asilo y refugio. En lugar de ello, la única prioridad y actuación real (que se ejecuta con celeridad y a la que se asignan presupuesto y recursos humanos), es el blindaje de las fronteras marítimas y terrestres, la violación sistemática de los derechos humanos y de la legislación internacional de asilo y refugio, así como a la externalización de las fronteras (transfiriendo a terceros países como Turquía o Marruecos, a cambio de mucho dinero y otras ventajas, la función de devolver ilegalmente a sus países a las personas refugiadas). Como si pagar para que acepten deportaciones ilegales e inhumanas nos hiciera menos responsables de las mismas.

Pero no solamente existen fronteras físicas y administrativas que impiden la acogida de las personas en busca de refugio, también hay poderosas fronteras morales, líneas de división invisibles pero extremadamente eficaces porque alimentan el rechazo y la indiferencia. Las fronteras morales se construyen a través de los discursos, por tanto, romper esas fronteras significa contribuir a construir nuevas representaciones de las personas refugiadas, es decir, a construir nuevos discursos.

Creemos que, en el contexto de la actual crisis humanitaria que sufren las personas en busca de refugio, es fundamental llevar a cabo acciones consensuadas, creativas y basadas en el conocimiento científico para prevenir actitudes negativas y conductas hostiles hacia las personas que se acogerán en nuestra sociedad. Y, también, porque el discurso del miedo hacia las personas refugiadas tiene un impacto negativo en toda la población migrante y, además, alimenta una lógica insolidaria que puede afectar a cualquier colectivo en situación de vulnerabilidad. Trabajar eficazmente en la comunicación social a favor de la acogida de personas refugiadas es una oportunidad para reforzar valores y principios de justicia y de solidaridad que la retórica de "los recortes necesarios" ha puesto en entredicho y, asimismo, para repensar los límites y los desafíos de la comunicación social antirracista.

\section{Indiferencia y distancia social}

Frente a las migraciones forzosas el papel de la sociedad civil es ambivalente: se observan respuestas organizadas y espontáneas tanto de profundo rechazo xenófobo y racista, como de verdadera acogida y solidaridad.

La inmovilidad y la indiferencia de parte de la sociedad y de las instituciones europeas frente a la crisis de humanidad vivida por la población refugiada es el reflejo de una profunda paradoja: vivimos en sociedades que consideran los derechos humanos y los valores democráticos como el núcleo central de nuestra identidad, pero nos mostramos apáticos e indiferentes o, incluso beligerantes, hacia personas que buscan refugio.

Después de los últimos atentados en varias ciudades de Europa el discurso dominante de las instituciones europeas ha sido el de oponer a la barbarie del terrorismo la defensa de los valores democráticos, aplicando al mismo tiempo y, sin embargo, 
una contundente violación sistemática de los derechos humanos de las personas que huyen del terror pidiendo socorro y esperando protección.

La indiferencia no afecta solamente a las instituciones, sino también a la sociedad civil. En una época caracterizada por la interconexión y la simultaneidad de los intercambios sociales, paradójicamente aumenta de forma desmesurada la distancia social que separa determinadas categorías de personas. Los medios de comunicación rompen las fronteras físicas con imágenes impactantes e información constante, pero la conexión entre las zonas en las cuales se vive la tragedia de las personas desplazadas forzosas y las regiones seguras que observan el "horror a distancia" está separada e interrumpida por fronteras que inhiben la indignación y el sentido de responsabilidad.

Como subraya Bauman, en la sociedad de la información "ser espectador ya no es la situación excepcional de unos pocos. Hoy en día todos somos espectadores, testigos de cómo se inflige dolor y del sufrimiento humano que eso causa" (2004, p. 240). Hoy, la excusa de no saber no es más una excusa válida y, lejos de disminuir la culpa, más bien la agrava, porque la indiferencia es una forma de justificación, legitimación y consentimiento de la injusticia. Es decir, el silencio y la indiferencia nos convierten en cómplices de lo que está sucediendo.

\section{Fronteras morales}

Necesitamos comprender cómo se configuran los límites de nuestro "espacio moral". El espacio moral es el espacio que involucra a las personas que consideramos que tienen derechos morales, por las cuales estamos dispuestos/as a hacer sacrificios, y hacia las cuales sentimos empatía o podemos sentirnos potencialmente responsables (Opotow, 1990). A menudo, sin ser conscientes de ello, nuestro espacio moral no es universal, sino que excluye a determinados grupos de personas. Por ejemplo, la idea de los derechos humanos universales puede ser un elemento central de nuestra visión del mundo pero, en la práctica, cuando sufren o cuando se violan los derechos de algunas personas nuestra empatía y nuestra indignación son mínimas.

La exclusión del espacio moral afecta a muchas categorías de personas, en momentos y en contextos diferentes: personas diversamente hábiles, mujeres, personas en situación de pobreza, personas inmigrantes, etc. Potencialmente todos y todas podemos, en algún momento, ser excluidos y excluidas del espacio moral de la mayoría y esto es oportuno y necesario recordarlo porque la lucha por los derechos de las personas refugiadas no es solamente la defensa de un colectivo particular, sino una ocasión de luchar por una nueva cultura de la solidaridad.

Cabe preguntarse entonces, ¿por qué algunos grupos de personas son excluidos de nuestro espacio moral y otros no? Más en particular: ¿por qué en algunos casos, las personas refugiadas se quedan fuera de nuestro espacio moral? Y, ¿cuáles son las 
razones que determinan que las personas refugiadas no "merezcan" nuestra preocupación? Pues porque las fronteras que impiden que personas en fuga de la violencia puedan encontrar refugio no son solamente políticas y administrativas. La población del mundo está separada, además, por fronteras simbólicas (Lamont y Molnár, 2002) que marcan las diferencias entre "nosotros" y "ellos". Las fronteras simbólicas son líneas imaginarias, que definen la identidad, las características y los límites de los grupos. Se articulan a través de imágenes, acciones, formas discursivas, esquemas mentales, emociones, sentimientos y símbolos que constituyen representaciones sociales compartidas. Por ejemplo, definen la diferencia entre nacionales y personas extranjeras, entre gitanos/as y payos/as, entre hombres y mujeres, etc. En muchos casos las fronteras simbólicas son muy porosas, permeables y dinámicas, en otros casos son rígidas, impermeables y fijas. Cuando estas fronteras simbólicas son rígidas o separan a grupos en conflicto, en competición, o a grupos cuya relación se caracteriza por una fuerte asimetría de poder, se transforman en fronteras morales. Es decir, líneas de separación simbólicas que colocan a determinados grupos fuera de los márgenes en los que nos sentimos obligados a aplicar normas morales y de justicia.

Las fronteras morales juegan un papel muy importante en la justificación de la desigualdad: las fronteras morales nos permiten aceptar y condescender actos que nos resultarían inconcebibles al interior de nuestro espacio moral. Pensemos, por ejemplo, en la violencia extrema en las fronteras, en las devoluciones ilegales sin garantías que violan todos los derechos, en las diferentes formas de discriminación, en la existencia de los Centros de Internamiento de Extranjeros (CIE), donde se priva de libertad a personas que han cometido una falta administrativa y no un delito, o en la omisión de socorro hacia las personas que buscan refugio.

La construcción de las fronteras morales permite dar coherencia moral a un sistema inmoral que deja morir a miles de personas en busca de refugio, sin que por ello se ponga en duda la humanidad y justicia del sistema. Las fronteras morales nos impiden reconocer la humanidad, y por tanto los derechos morales y jurídicos, de las personas en busca de refugio y protección. Las fronteras morales son extremadamente eficaces porque están dentro de las mentes de las personas: garantizan que las personas a las que tendríamos el deber jurídico y moral de socorrer no solamente se queden fuera del alcance de la justicia, sino también fuera de la preocupación moral de los grupos mayoritarios (Bierbrauer, 2000).

\section{Medios de comunicación, sociedad civil y mediapolis}

Un aspecto clave para entender la indiferencia o el rechazo frente a la llegada de personas desplazadas forzosas es que la mayoría de la población española no tiene una relación directa con las personas que buscan refugio, sino mediada por los medios de comunicación y, en general, lo que Silverstone (2010) denomina mediapolis. 
Hablamos de mediapolis, y no solamente de medios de comunicación, porque hoy en día, gracias a la enorme expansión de las nuevas tecnologías y, en particular, de las redes sociales, toda persona o grupos de personas pueden, potencialmente, generar un discurso público. Si en las décadas anteriores los medios de comunicación tradicionales tenían casi el monopolio absoluto del discurso público, hoy en día están cobrando cada vez más protagonismo y cada vez más poder de definición de la realidad las redes sociales. Es esa capacidad para construir el relato dominante y para nombrar las cosas, lo que confiere a la mediapolis su enorme poder de definición y construcción de la realidad.

La imagen que tenemos de las personas refugiadas, la forma en la cual representamos nuestra crisis de humanidad que les afecta, sus causas y sus consecuencias, no depende solamente de los medios de comunicación, sino de la interacción y retroalimentación constante entre medios de comunicación, discurso político y discurso social-popular.

Como subraya Silverstone (2010), la mediapolis tiene el poder de "proveer -con distintos grados de coherencia- los marcos de referencia (o los mundos de referencia) para la presentación del otro, hasta el punto que, de hecho, acaban definiendo el espacio moral en el que nos exponemos al otro, y al mismo tiempo sugieren (exigen, condicionan) en la audiencia una respuesta moral similar, en tanto que ciudadanos potenciales o reales" (p. 22).

Siguiendo la propuesta de Silverstone, los medios de comunicación, a través de un intenso trabajo de construcción de fronteras definen la "distancia apropiada" entre quien mira cómodamente la televisión y quien sufre una injusticia. La distancia apropiada es la distancia que nos permite sentirnos informados, entristecernos o conmovernos frente al sufrimiento de las personas que huyen y necesitan protección, pero sin sentirnos responsables, sin sentirnos culpables, sin poner en discusión nuestro estilo de vida, nuestro sistema, nuestras instituciones y la violencia que ejercen.

\section{El discurso del miedo}

Los medios de comunicación, el discurso político y el flujo de información en las redes sociales influyen fuertemente en los temas sobre los cuales fijamos nuestra atención. Si una imagen, un acontecimiento o un tema son dominantes en la mediapolis, es muy probable que estén muy presentes en la opinión pública; y, al contrario, si algunos aspectos de la realidad no son visibilizados por la mediapolis, muy difícilmente estarán presentes en el discurso popular. En este sentido la agenda mediática, es decir la lista de asuntos o temas dominantes en la mediapolis, influye en la agenda pública, en la lista de temas que la sociedad civil considera importantes. Por ejemplo, si en la mediapolis se habla mucho de seguridad, terrorismo, amenaza del islam o competición por 
los recursos limitados a la hora de hablar de la llegada de personas refugiadas, es muy probable que estos sean los temas dominantes en la agenda pública.

La mediapolis no se limita a definir la agenda, sino que influye también en nuestra forma de pensar en determinados temas. Los medios de comunicación ofrecen siempre, explícita o implícitamente, un determinado encuadre de la noticia que vehicula determinados valores, creencias y expectativas que influyen en las personas destinatarias. El encuadre se puede construir y trasmitir de forma más o menos sutil a través de diferentes recursos semánticos como, por ejemplo, la fotografía o el lugar que ocupa la noticia en un periódico. Todos estos elementos conforman un marco de referencia que influye en nuestra forma de interpretar la información.

\section{El enfoque securitario y las nuevas formas de racismo}

El marco de referencia negativo dominante en Europa, relacionado con la llegada de personas desplazadas forzosas y necesitadas de protección, es lo que podríamos denominar el enfoque securitario, caracterizado por la representación de la persona en búsqueda de refugio como amenaza: representa un peligro porque a menudo está en el centro del imaginario sobre criminalidad; compite por el acceso a recursos que, sobre todo en épocas de crisis, son limitados (educación, trabajo, vivienda, servicios sociales etc.); y es una amenaza simbólica en el sentido de que atenta contra los valores tradicionales e identitarios.

El enfoque securitario y el discurso del miedo son algunas de las expresiones más comunes de las nuevas formas de racismo contemporáneo. La historia del racismo nos enseña que se trata de un fenómeno que ha sabido adaptarse y transformarse según las circunstancias y los contextos históricos, sociales, culturales y políticos. De hecho, "no existe un racismo invariable, sino unos racismos que forman un espectro abierto de situaciones" (Balibar y Wallerstein, 1991, p. 67).

Un aspecto clave de las dinámicas racistas contemporáneas es la existencia de un círculo vicioso, entre racismo institucional, racismo social y medios de comunicación, en el sentido que el discurso del miedo, característico del enfoque securitario, se retroalimente y se desarrolla gracias a la interacción entre el discurso institucional, la opinión pública y los medios de comunicación.

Son numerosas las manifestaciones en Europa de racismo contemporáneo que se pueden inscribir en este enfoque securitario: la existencia de los Centros de Internamiento de Extranjeros ( $\mathrm{ClE}$ ), los controles policiales arbitrarios en las calles por fenotipo, las expulsiones ilegales del territorio nacional, el surgir de nuevos movimientos políticos islamófobos como PEGIDA, el auge de los partidos de extrema derecha y las políticas restrictivas en materia de asilo. 
De la unión del racismo institucional con el racismo social nace lo que Rivera (2010) ha denominado un racismo "democrático": un racismo que evita la acusación de "racismo" porque evita hablar de razas y se basa en dos principios aceptados socialmente: la autodefensa y la preferencia nacional (Dal Lago, 1999). Es decir, el discurso racista se alimenta del miedo y justifica el rechazo de las personas inmigrantes y que solicitan asilo así como la violencia hacia ellas; pero no en nombre de una supuesta diferencia racial, sino porque considera que es legítimo defenderse frente la amenaza que representan estas personas y porque, en una época de crisis, hay que dar prioridad a "los nuestros" (preferencia nacional).

En este contexto, ¿es todavía oportuno hablar de racismo? Aunque no se haga explícitamente referencia a las razas es importante tener en cuenta que el enfoque securitario y el discurso de miedo se pueden comprender y combatir solamente si se interpretan como nuevas formas de racismo.

En línea de lo que hemos planteado Aguilar y Buraschi (2016), podemos identificar dos elementos fundamentales del racismo: la dominación y la racialización. Dominación en tanto que el racismo es un principio estructurador del sistema y una manifestación concreta del poder y la opresión de un grupo sobre otros. Racialización significa que las diferencias fenotípicas, sociales, culturales, religiosas etc. se piensan como si fueran naturales, esenciales, como si fueran marcadores de una supuesta raza. El racismo implica una diferenciación esencial y radical entre grupos humanos, el reduccionismo de la complejidad de las personas a pocas características vinculadas con un grupo (identidad cultural, fenotipo, pertenencia étnica, religión, idioma) y una relación determinista entre estas características y la forma de ser de una persona.

Entendemos el racismo como "un sistema de dominación de un grupo sobre otro basado en la racialización de las diferencias, en el que se articulan las dimensiones interpersonal, institucional y cultural. Se expresa a través de un conjunto de ideas, discursos y prácticas de invisibilización, estigmatización, discriminación, exclusión, explotación, agresión y despojo" (Aguilar y Buraschi, 2016, p. 34).

\section{Cómo se construyen las fronteras morales}

El enfoque securitario se construye en la mediapolis a través de tres procesos (Buraschi y Aguilar, 2016): la negación, la diferenciación y la construcción del otro como amenaza. Estos procesos permiten a las personas superar la contradicción que existe entre sus valores universales y la indiferencia frente a la violación de los derechos humanos básicos de las personas en busca de refugio y protección.

La planificación de acciones comunicativas de sensibilización tiene que tener en cuenta estos procesos, entender su lógica y su retórica, para poder crear discursos alternativos eficaces. 
A) La negación. El primer mecanismo de construcción de las fronteras morales en la mediapolis es la negación. Cuando en la mediapolis se habla de las personas refugiadas podemos identificar al menos tres formas de negación (Cohen, 2001):

- Una negación literal, es decir una explícita negación de los hechos: como cuando se invisibiliza el sufrimiento de las personas, la violencia en las fronteras, o los diferentes grupos de personas refugiadas.

- Una negación implicatoria, que acepta lo sucedido, pero minimiza sus implicaciones sociales y políticas. Por ejemplo, cuando hablamos de la llegada de personas pero consideramos que se trata de inmigrantes económicos y no de personas refugiadas. O cuando se alimentan las dudas sobre la "genuinidad" de las demandas de asilo, favoreciendo la extensión de una idea de las personas demandantes asilo como aprovechadoras del sistema

- Una negación interpretativa, que niega la responsabilidad de las personas involucradas, atribuyendo las causas de lo sucedido a las propias víctimas (cuando se ocultan las causas de los conflictos y se oculta, por ejemplo, la responsabilidad de los países occidentales en la crisis, etc.).

B) La diferenciación. El segundo proceso que contribuye a la construcción de fronteras morales es la radical diferenciación entre nosotros/as y ellos/as. Los "otros", en nuestro caso las personas refugiadas, son presentados como una masa anónima, sin rostro, ni voz, se subrayan las diferencias, sobre todo culturales y religiosas en lugar que hacer hincapié en lo que nos acomuna.

C) La amenaza. Finalmente, el último proceso a través del cual se construyen las fronteras morales es la representación de las personas refugiadas como amenaza. A menudo se representan como una amenaza a nuestro estado de bienestar, porque pensamos que compiten con la población autóctona para los recursos limitados; una amenaza para la seguridad ciudadana y una amenaza a nuestros valores identitarios y culturales.

\section{Estrategias de resistencia frente a la barbarie}

La comunicación es el elemento clave de cualquier estrategia de resistencia, por el papel central que ocupa en todo proceso de dominación al crear significados, representaciones y construyendo la realidad. Como acertadamente nos recuerda Castells (2009): "El poder se ejerce fundamentalmente construyendo significados en la mente humana mediante los procesos de comunicación que tienen lugar en las redes multimedia globales-locales de comunicación de masas, incluida la autocomunicación de masas"; porque "la capacidad para emplear con éxito la violencia o la intimidación requiere el enmarcado individual y colectivo de las mentes" (p. 535). Y si todas las redes de poder lo ejercen influyendo en la mente humana principalmente, es a través de las redes multimedia de comunicación de masas como podemos construir lo que Holston 
(2008) Ilama "ciudadanía insurgente". Se trata de construir un contrapoder (intento deliberado de cambiar las relaciones de poder) que "se activa mediante la reprogramación de redes en torno a valores e intereses alternativos o mediante la interrupción de las conexiones dominantes y la conexión de redes de resistencia y cambio social" (Castells, 2012: 28).

Hemos intentado plantear en este texto cómo las fronteras morales se construyen, sobre todo, a través de procesos comunicativos que se producen y transmiten en la mediapolis, que no es otra cosa que la esfera pública mediada en la que la acción cívica y la participación tienen la oportunidad de crecer (Tufte, 2015). Esta mediapolis, aunque embrionaria e imperfecta, es un punto de partida necesario para la creación de un espacio vital global más efectivo. Este espacio mediado de visibilidad es, sobre todo, un espacio de potencial y posibilidad (Silverstone, 2007). Los criterios de hospitalidad, justicia y ética mediática son puntos de referencia basados en la moral que pueden contribuir a alcanzar una comunicación completamente efectiva en la mediapolis: ese espacio dialógico que "es a la vez una posibilidad social abarcante y una expresión de la diversidad empírica del mundo" (Silverstone, 2007).

Vivimos en una sociedad de riesgo en que prevalece la cultura del miedo y la inseguridad, por ello nuestro desafío fundamental es ayudar a establecer las bases para una "comunicación empática" (Tufte, 2015), capaz de deconstruir las realidades que desencadenan la inseguridad (Curbet, 2006). Por todo ello sostenemos que buena parte de las estrategias de resistencia se juegan en la mediapolis, pues de lo que se trata es de definir una nueva agenda y construir nuevos marcos de interpretación deconstruyendo los existentes (en este sentido, cualquier tipo de participación implica agencia). Existe una "potencial sinergia entre el ascenso de la auto-comunicación masiva y la capacidad autónoma de las sociedades civiles alrededor del mundo" (Castells, 2009: 303).

Basándonos en estas premisas, nuestra propuesta es la siguiente: Si la mediapolis es el espacio privilegiado de la definición de las fronteras simbólicas, es desde este espacio público mediático que podemos plantear, aunque sea de forma esquemática, algunas estrategias que pueden contribuir a la deconstrucción de las fronteras morales.

Si las fronteras morales son un dispositivo tanatopolitico que se articula a través de un proceso de negación - diferenciación - construcción del otro como amenaza, las estrategias de resistencia tendrán que desarrollarse a través de un proceso de hacer comprender - rehumanizar - responsabilizar.

\subsection{Comprender}

Sontag considera ingenua la idea según la cual el poder de las imágenes está en su capacidad de fomentar el repudio a la atrocidad o la insensatez. Para ella, se necesita algo más que conmoción, en la medida en que ver no es comprender. Hace falta comprensión del hecho: algo que las imágenes no brindan por sí mismas (Sontag, 2003: 
104). La mera aparición del otro en estado de crisis no basta para "comprometernos" con él ya que el efecto puede ser efímero o contrario: llevar a la negación y la indiferencia, por lo que no hay que confundir la conexión con la cercanía, la cercanía con el compromiso, o la visibilidad con la responsabilidad (Silverstone, 2010).

Es necesario visibilizar el sufrimiento sin espectacularizarlo, hacer comprender las causas y las implicaciones de la situación de las personas en busca de refugio, visibilizar la complejidad del problema, la relación que tiene con el sistema de desigualdad global; pero es también necesario visibilizar el coste social, político, ético y estratégico de la "indiferencia".

\subsection{Rehumanizar}

La fotografía de Aylan nos ha mostrado los efectos de una ruptura (lamentablemente efímera) de las fronteras morales: el tipo de imagen, su tratamiento mediático, conocer su nombre y su familia, su ropa, el fenotipo, su edad o su posición en la playa han contribuido a rehumanizar a las personas refugiadas. El desafío es cómo rehumanizar a las personas refugiadas sin caer en el sensacionalismo, puesto que apostar por el dramatismo es fácil a corto plazo, pero peligroso a largo plazo: el drama se normaliza, nos acostumbramos a la tragedia o activamos mecanismos de defensa que pueden llegar a culpabilizar a las víctimas.

La investigación psicosocial nos ha dado numerosas claves, fundamentadas en un riguroso trabajo científico, para poder fomentar la empatía, la toma de perspectiva y rehumanizar a colectivos que suelen estar excluidos de nuestra esfera moral. Se trata de operativizar estas claves, y además, de forma participativa y dialógica, generar propuestas creativas que nos permitan llegar a rehumanizar a las personas refugiadas, para que vuelvan a ser sujetos de derechos y para que la indignación frente a su situación sea realmente movilizadora.

Frente a la diferenciación radical, es necesario construir un nuevo "nosotros", más inclusivo y complejo. Se trata de presentar a las personas refugiadas como sujetos y no como masa anónima, mostrar su heterogeneidad, visibilizar la complejidad de las personas y sus múltiples identidades. Subrayar los elementos comunes ayuda a romper las barreras entre grupos y facilita la identificación. Conocer la historia de una persona, conocer su identidad, darle voz y rostro aumenta la empatía hacia ella. Nombrar y ser nombrado, estar presente y hacer presentes a quienes son rechazados y devueltos al infierno, es un modo necesario de resistencia: si la indiferencia es un elemento clave de la lógica de dominación, la empatía es una forma de "disidencia emocional" (Zamperini, 2007). 


\subsection{Responsabilizar}

La rehumanización implica responsabilizarse y comprometerse en el terreno de la acción. Porque la inacción nos recolocaría de nuevo en el campo de la indiferencia y la desconexión moral. Y actuar sólo es posible si nos responsabilizamos de la situación-problema.

Para fomentar la responsabilidad no es suficiente visibilizar el sufrimiento, sino dar elementos para su comprensión, identificar las causas del problema, sobre todo aquellas que tienen que ver con nosotros, plantear posibles soluciones, crear las condiciones para que las personas puedan intervenir. Si las causas nos son claras podemos culpar a las víctimas de lo que está pasando para proteger nuestra visión del mundo. Por otra parte el sufrimiento sin solución, sentirse incapaces de intervenir o, siendo capaces, no tener la posibilidad de intervenir nos genera ansiedad y frustración y al final preferimos "no mirar" para no estar mal.

Hacer comprender, rehumanizar y responsabilizar son estrategias de resistencia que permiten "repolitizar el sufrimiento" (Valverde, 2015). La tanatopolítica despolitiza (quita todo contenido político a los temas sociales en general, y a la situación de las personas migrantes/refugiadas que habitan en la zona del no-ser en particular) manipulando el lenguaje, culpabilizando, negando e invisibilizando las causas y los contextos. La necesaria repolitización del sufrimiento sólo puede ocurrir cuando llenemos de contenido político la realidad, nombrando las injusticias y generando un nuevo relato.

\section{Nota:}

Este artículo forma parte del Proyecto I+D+I DER2015-65840-R "Diversidad y Convivencia: los derechos humanos como guía de acción", Programa Estatal de Investigación, Desarrollo e Innovación orientada a los retos de la sociedad, Ministerio de Economía y Competitividad; y del Proyecto de intervención "Claves para la acogida comunitaria de personas refugiadas: comunicación social, antirracista y participativa”, financiado por el Gobierno de Canarias, en colaboración con la Universidad de La Laguna a través de su Fundación General y realizado por la Asociación Educación para la Convivencia Mosaico Canarias

\section{Referencias Bibliográficas}

Aguilar-Idáñez, M $M^{a}$ J. y Buraschi, D. (2016). Del racismo y la construcción de fronteras morales a la resistencia y el cambio social: La sociedad civil frente a las migraciones forzosas. Política Social y Servicios Sociales (Septiembre-2016), XXXIII (111), 29-44.

Balibar, E. y Wallerstein, I. (1991). Raza, nación y clase. Madrid: lepala.

Bauman, Z. (2010). Living on borrowed time. Cambridge: Polity Press.

Biebrauer, G. (2000). Social Justice and Political Ideology in an immigrant country. In T. Baums, K.J. Hopt \& N. Horn (Eds.), Corporations, Capital Market and Business in the Law (pp. 89- 99). Londres: Kluwer Law International.

Castells, M. (2009). Comunicación y poder. Madrid: Alianza. 
Cohen, S. (2001). States of Denial: Knowing About Atrocities and Suffering. Cambridge: Polity Press.

Curbet, J. (2006). La globalización de la (in)seguridad. La Paz: Plural.

Holston, J. (2008). Insurgent Citizenship. Disjunctions of Democracy and Modernity in Brazil. Princeton: University of Princeton.

Lamont, M. y Molnár, V. (2002). The study of boundaries in the social sciences. Annual review of sociology, 28, 167-195.

Opotow, S. (1990). Moral exclusion and injustice: An introduction. Journal of Social Issues, 46(1), 1-20.

Silverstone, R. (2010). La moral de los medios de comunicación. Sobre el nacimiento de la polis de los medios. Madrid: Amorrortu.

Sontag, S. (2003). Ante el dolor de los demás. Barcelona: Círculo de Lectores.

Tufte, T. (2015). Comunicación para el cambio social. La participación y el empoderamiento como base para el desarrollo mundial. Barcelona: Icaria.

Valverde, C. (2015). De la necropolítica a la empatía radical. Violencia discreta, cuerpos excluidos y repolitización. Barcelona: Icaria.

Zamperini, A. (2007). L'indifferenza. Conformismo del sentire e dissenso emozionale. Torino: Einaudi.

María José Aguilar Idáñez

Directora del GIEMIC (Grupo Interdisciplinar de Estudios sobre Migraciones, Interculturalidad y Ciudadanía)

y Directora del Master on-line en Inmigración e Interculturalidad.

Email: mariajose.aguilar@uclm.es

Daniel Buraschi

Pedagogo social por la Universidad de Padua, investigador del GIEMIC (UCLM) y miembro de OBITen (Observatorio de la Inmigración de Tenerife).

Correspondência:

María-José Aguilar Idáñez

Facultad de Ciencias de la Educación y Humanidades

Edificio Gil de Albornoz

Avda. de los Alfares, 44

16071 Cuenca (España)

Data de submissão: Janeiro 2016

Data de avaliação: Março 2016

Data de publicação: Setembro 2017 